Book Review

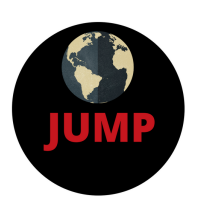

ISSN: 2574-3465 Print/ ISSN: 2574-3481 Online

Volume 2, Issue 1 (2018), pp. 112-114

(C) Journal of Underrepresented and Minority Progress

http://minorityprogress.org/

doi: $10.5281 /$ zenodo. 1322160

\title{
A Book for your Boss: A Great Book the Right People Won't Read
}

\author{
Bob Eckhart \\ The Ohio State University, USA \\ WHU-OSU Center for American Culture
}

Before describing the issue this book addresses and the content of each chapter, let me start by saying International Student Engagement: Strategies for Creating Inclusive, Connected, and Purposeful Campus Environments by Chris R. Glass, Rachawan Wongtrirat, and Stephanie Buus, should be required reading for everyone who will probably never read it. If you have found it and read it, chances are you are already in close contact with the international students at your institution, listening to them talk about their day-to-day realities and are trying to improve them. You are probably also aware of the strategies that work for your institution which are necessarily unique to its size, history, campus and community environment, etc. The

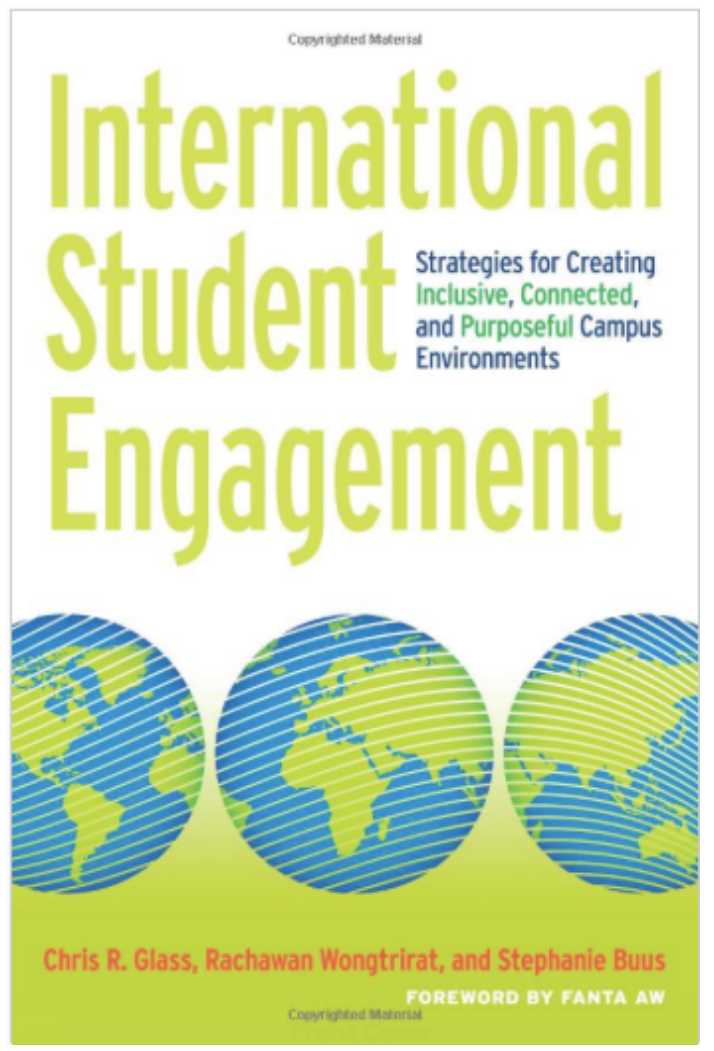
act of finding and reading this book shows that you are interested in improving the quality of experience for international students and you have taken small steps to do something about it. So, the challenge becomes finding ways to get this important book into the hands of every upper-level administrator across the country.

These are the decision-makers who are chairing committees focusing on meeting the needs of international students and fiscal officers who are controlling budget allocations to serve them. In many cases, those administrators are also the ones deciding to plug deficits with international tuition dollars without considering whether their institution is equipped to be a good host to students from abroad. What we've witnessed in higher education in the U.S. in the last 10 years is a Ready, Shoot, ...AIM! attitude toward international student enrollment. That is the crucial issue this book is trying to address, by proposing strategies and solutions for making campuses better places for international students.

But there's good news, I think--toward 
the end of this highly-concentrated yet easy-to-read book is the real key to creating inclusive, connected, and purposeful environments: creating a sense of belonging on campus (Glass, Buus, \& Wongtrirat, 2015, p. 83). This actually draws on the research of my colleague at Ohio State, Terrell Strayhorn, which focuses on the experiences of sexually-diverse students and students of color. The good news is that your institution probably already has strategies in place for promoting belongingness, even if those strategies are currently designed with underrepresented students in mind instead of international ones. This strategy is listed in the recommendations in the final chapter: "Connect international initiatives to existing efforts for student engagement and success" (Glass, Buus, \& Wongtrirat, 2015, p. 105).

This is an absolutely vital point: we aren't reinventing the wheel when we seek to meet the needs of international students. If your institution has a diversity plan, has an office of diversity and/or inclusion, has a multicultural center, or at the least has a statement recognizing the value of diversity in the usual terms of ethnicity, gender, and religion, then it isn't such a large leap to include global diversity in this. The way you do this is by convincing upper-level administration that the only way to achieve academic excellence in the $21^{\text {st }}$ century is by having an internationalized campus where domestic students have the opportunity to develop global competencies and global intelligence. These attributes will prepare them for living in a global society and working in a global economy. International students, quite literally, bring the world to your institution whether you are in rural Wisconsin, suburban Philadelphia, or downtown Boulder.

\section{REVIEW}

In the beginning of the book, the Introduction provides the necessary, almost incomprehensible statistics about exponentially increasing international enrollment-there are roughly a million international students in the U.S. (Glass, Buus, \& Wongtrirat, 2015, p. 1) - and a quote from a student who lays the issue bare: "Universities are eager to accept our fees-but are they doing enough to support young people like me who come from far away to study?" (p. 2, cited in Paudel, "What It's Like to be an International Student, Guardian, 9 Sept. 2013).

The organization of each chapter is consistent-discussions of issues, interesting statistics from the Global Perspective Inventory, student voices, and relevant case studies from an array of $\mathrm{big} / \mathrm{small}$, rural/urban, research one/liberal arts institutions. The student voices are probably the most powerful and are from undergraduates and graduate students from all over the world. However, given the realities of the highly-documented recent enrollment surge of Chinese undergraduates - and their often, confounding presence on campuses--their voices seemed strangely missing, as many readers might in fact be reading this book with the express intention of creating inclusive campus environments specifically with Chinese undergraduates in mind.

The chapters themselves are well-organized and address cultural diversity in the classroom (Ch. 1), encouraging international students to participate in campus leadership (Ch. 2). The chapters also speak to the importance of social networks in international student engagement (Ch. 3), the impact of technology on the international student experience (Ch. 4), belongingness (Ch. 5), and timely recommendations (Ch. 6). All of them include accessible anecdotes and valuable citations for future reading. Overall, this quick, light read is as accessible as it is important. You could and should, try to slip it into the bag of your senior international officer before his or her next flight abroad. Even those of us who have worked closely with international students for a decade or more, and who still work with them every day, can benefit from reading it because it will expose us to strategies at work at other institutions.

And for those people not working with international students on a daily basis - but perhaps making decisions that affect them - International Student Engagement: Strategies for 
Creating Inclusive, Connected, and Purposeful Campus Environments accurately portrays the lived experiences of both the students themselves and those folks whose responsibility it is to work with them. In many cases, those who volunteer to pick up the slack assume this responsibility because at many institutions, very often there isn't anyone else to do this important work. It is work that must be done in order for us to be good hosts to students who arrive on our campuses from all over the world with their hopes and dreams. This book may help us meet their justifiably high expectations of how they will be received and welcomed into our campus communities.

\section{REFERENCES}

Glass, C. R., Buus, S., Wongtrirat, R. (2015). International student engagement. Sterling, VA: Stylus Publishing.

Paudel, S. (September 12, 2013). Poor, isolated, and far from home: what it's like to be an international student. The Guardian.

Bob Eckhart is the Executive Director of the Combined ESL Programs at The Ohio State University and has taught over 2500 international students in the last 20 years, both in the U.S. and abroad. He is also the Director of the WHU-OSU Center for American Culture (a project of the Department of State) on the campus of Wuhan University in Hubei Province, P.R. China. Email: eckhart.5@osu.edu. 